\title{
Experimental repair of phrenic nerve using a polyglycolic acid and collagen tube
}

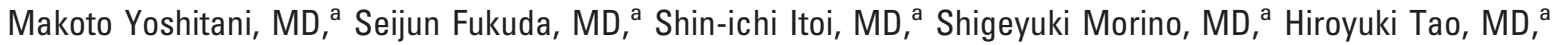 \\ Akira Nakada, MD, ${ }^{a}$ Yuji Inada, MD, ${ }^{a}$ Katsuaki Endo, MD, ${ }^{b}$ and Tatsuo Nakamura, MDa
}

丹 Supplemental material is available online.
From the Department of Bioartificial Organs, Institute for Frontier Medical Sciences, ${ }^{\text {a }}$ Kyoto University; and Nerve Regeneration Research Center Kyoto, ${ }^{\mathrm{b}}$ Kyoto, Japan.

This work was supported in part by a grant from the Ministry of Education, Science, Sports, and Technology of Japan (RR 2002; Project for the realization of regenerative medicine: Research field for development of stem cell therapy).

Received for publication April 4, 2006; revisions received Aug 12, 2006; accepted for publication Aug 30, 2006

Address for reprints: Tatsuo Nakamura, MD, Department of Bioartificial Organs, Institute for Frontier Medical Sciences, Kyoto University, 53 Kawahara cho, Sakyo-ku, Kyoto 606-8507, Japan (E-mail: nakamura@ frontier.kyoto-u.ac.jp).

J Thorac Cardiovasc Surg 2007;133:726-32 $0022-5223 / \$ 32.00$

Copyright () 2007 by The American Association for Thoracic Surgery

doi:10.1016/j.jtcvs.2006.08.089
Objective: The feasibility of a nerve guide tube for regeneration of the phrenic nerve with the aim of restoring diaphragmatic function was evaluated in a canine model.

Methods: The nerve tube, made of woven polyglycolic acid mesh, had a diameter of $3 \mathrm{~mm}$ and was filled with collagen sponge. This polyglycolic acid-collagen tube was implanted into a 10-mm gap created by transection of the right phrenic nerve in 9 beagle dogs. The tubes were implanted without a tissue covering in 5 of the 9 dogs (group I), and the tubes were covered with a pedicled pericardial fat pad in 4 dogs (group II). Chest x-ray films, muscle action potentials, and histologic samples were examined 4 to 12 months after implantation.

Results: All of the dogs survived without any complications. X-ray film examination showed that the right diaphragm was paralyzed and elevated in all dogs until 3 months after implantation. At 4 months, movement of the diaphragm in the implanted side was observed during spontaneous breathing in 1 dog of group I and in 3 dogs of group II. In the dogs showing diaphragm movement, muscle action potentials were evoked in the diaphragm muscle, indicating restoration of nerve function. Regeneration of the phrenic nerve structure was also examined on the reconstructed site using electron microscopy.

Conclusion: The polyglycolic acid-collagen tube induced functional recovery of the injured phrenic nerve and was aided by coverage with a pedicled pericardial fat pad.

$\mathrm{M}$ ore than $95 \%$ of the phrenic nerve consists of motor neurons regulating the complex movement of the diaphragm. Phrenic nerve paralysis can occur as a result of congenital disorder, trauma, or surgical removal of adjacent organs, and this may cause diaphragm dysfunction, ranging from asymptomatic radiographic abnormality to severe pulmonary failure requiring prolonged mechanical ventilation, and other associated morbidities or even death. ${ }^{1}$

Diaphragm pacing, diaphragm plication, and reconstruction of the phrenic nerve have been tried as treatments for phrenic nerve paralysis. Direct anastomosis or autografting has been applied for the reconstruction of the phrenic nerve..$^{2-6}$

In surgery on peripheral nerves, reconstruction with nerve guide tubes has been effective. A variety of synthetic materials, such as silicone, polyglycolic acid (PGA), and polylactic acid, have been examined experimentally for use as artificial nerve tubes. Bioabsorbable tubes made of synthetic polymer have been shown to assist axonal elongation. ${ }^{7-14}$ We developed a PGA-collagen tube and showed in previous studies that it can induce nerve regeneration across an 80-mm gap with functional recovery in a canine nerve defect model. ${ }^{10-13}$ This PGA-collagen tube has been applied clinically since 2002 for human patients with peripheral nerve injuries, and some promising results have been reported. ${ }^{15,16}$ However, these successes were achieved mainly in a subcutaneous vascular-rich environment or by using muscle tissue, ${ }^{10-14,17,18}$ and so far there have been no reports of successful 


\section{Abbreviations and Acronyms \\ MAP $=$ muscle action potential \\ PGA $=$ polyglycolic acid}

regeneration of the phrenic nerve in the thoracic cavity using a nerve guide tube, perhaps because the phrenic nerve is located in an environment completely different from that of other peripheral nerves.

The aim of the present investigation was to evaluate the use of the nerve guide tube currently being applied clinically $^{14,15}$ for regeneration of the transected phrenic nerve and to assess the resulting morphologic and functional recovery of the phrenic nerve.

\section{Materials and Methods}

The nerve tube was prepared as described in our previous report. ${ }^{14}$ Briefly, the tube was made of braided PGA fiber, and both its inner and outer surfaces were coated with $1 \% \mathrm{w} / \mathrm{v}$ collagen hydrochloride solution and dried. This coating process was repeated 10 times. The collagen used (provided by Nippon Meat Packers, Osaka, Japan) was atelocollagen extracted from young porcine skin and confirmed to be free of viral contamination (Figure 1, A). This collagen consists of type I collagen (70\%-80\%) and type III collagen (20\%-30\%), and has low antigenicity as a result of removal of the telopeptides from both ends of the collagen molecules. ${ }^{13}$

The inner side of this tube was then filled with collagen sponge with piled thin film structure to induce nerve regeneration (Figure $1, B)$. Each tube was $3 \mathrm{~mm}$ in diameter and $20 \mathrm{~mm}$ in length, and sterilized with ethylene oxide gas before implantation.

\section{Animal Experiments}

Nine adult beagle dogs of arbitrary sex, weighing 10.0 to $15.0 \mathrm{~kg}$, were used. Premeditations were done with ketamine $(10 \mathrm{mg} / \mathrm{kg}$ intramuscularly) and xylidine ( $2 \mathrm{mg} / \mathrm{kg}$ intramuscularly). The dogs were then intubated, and general anesthesia was maintained under mechanical ventilation using $50 \%$ of nitrous oxide gas containing $1.0 \%$ to $1.5 \%$ Fluothane, without muscle relaxant. The right lateral thoracotomy was performed through the fifth intercostal space, and a 3-cm length of the right phrenic nerve was detached from the pericardium, starting $10 \mathrm{~cm}$ from the diaphragm, leaving a $7-\mathrm{cm}$ distal stump running along the inferior vena cava.

Electrophysiologic examination was carried out to check the function of the diaphragm before implantation of the guide tube. One pair of needle electrodes was placed on the proximal site of the phrenic nerve, and 1 pair was placed on the diaphragm. After stimulation of the proximal phrenic nerve, muscle action potentials (MAPs) in the diaphragm were checked.

The phrenic nerve was then transected with a scalpel, and a $1-\mathrm{cm}$ segment was removed. The nerve tube (PGA-collagen tube) was implanted into this 1-cm gap and fixed with epineural 7-0 Prolene (Ethicon, Somerville, NJ) interrupted sutures with microsurgical technique. The implanted PGA-collagen tube was $20 \mathrm{~mm}$ in length and $3 \mathrm{~mm}$ in diameter, and both the cut ends of
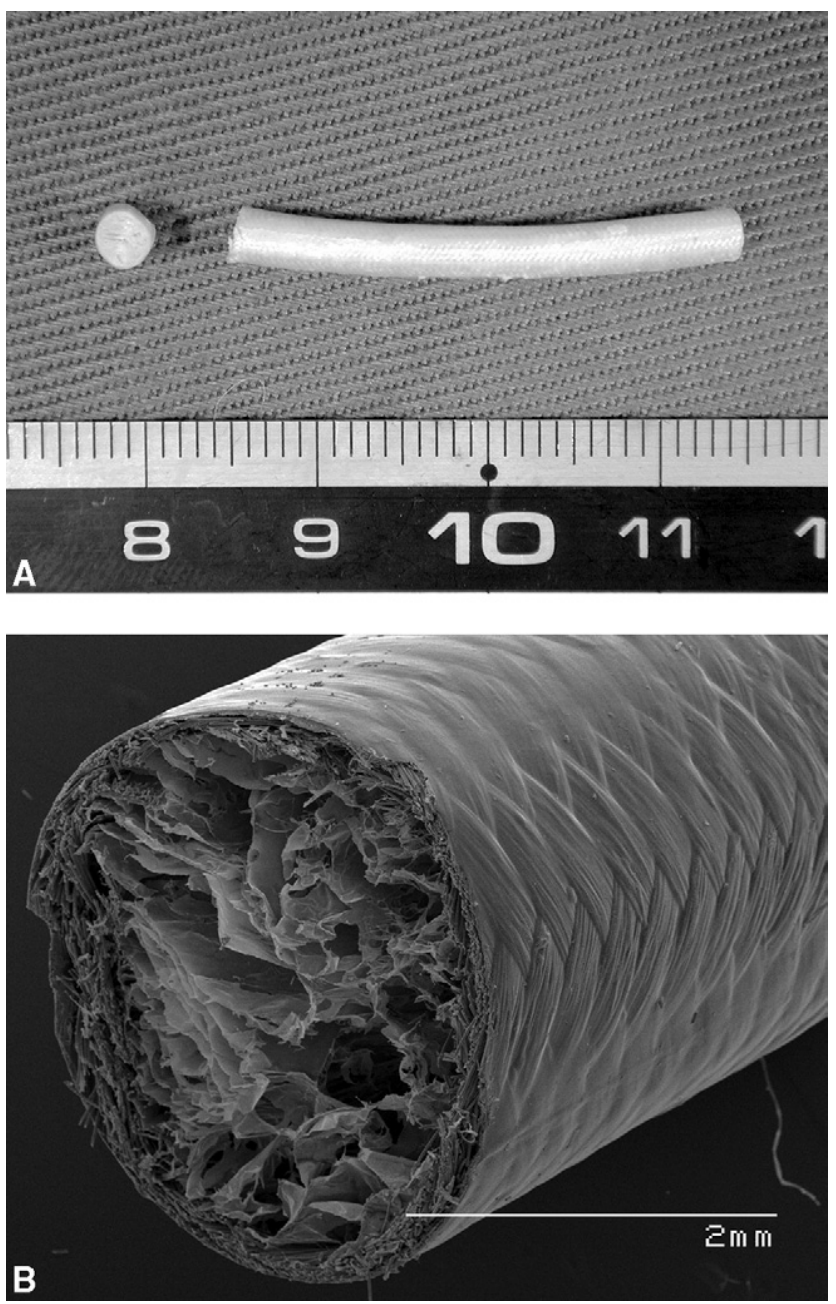

Figure 1. A, Overview of PGA-collagen tube filled with collagen of piled thin film structure (left, transverse section). B, Scanning electron micrograph image of a PGA-collagen nerve tube: The inner space of the tube is filled with collagen of piled thin film structure.

the phrenic nerve were inserted $5 \mathrm{~mm}$ into the nerve tube $(5 \mathrm{dogs}$, group I) (Figure 2).

In the other 4 dogs (group II), the site of nerve reconstruction was covered with a pericardial fat pad pedicle that was detached from the pericardium, leaving the proximal part to maintain the blood supply from the internal thoracic artery (Figure 3). The left phrenic nerve was left intact in all dogs.

After reinflation of the lung, a temporary drainage tube was removed and the thorax was closed. Each animal was administered an intramuscular injection of $100 \mathrm{mg}$ of ampicillin per day for 3 days.

\section{Evaluation}

Radiologic examination. The movement of the diaphragm was checked periodically by analysis of $\mathrm{x}$-ray film images 


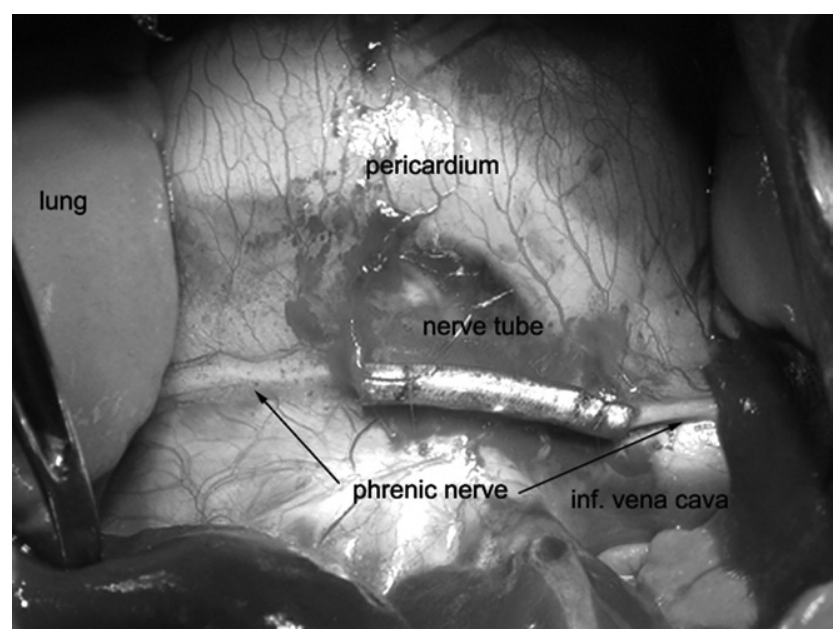

Figure 2. Intraoperative view after implantation of a PGAcollagen tube: The cut ends of the phrenic nerve on both sides were inserted $5 \mathrm{~mm}$ into the nerve tube.

(BV300, Philips Medical Systems, Best, The Netherlands) under spontaneous respiration with intramuscular administration of ketamine $(5 \mathrm{mg} / \mathrm{kg})$ and xylidine $(1 \mathrm{mg} / \mathrm{kg})$.

Electrophysiologic and histologic examinations. Five dogs in which diaphragm movement was observed by radiography underwent open thoracotomy 4 to 12 months after guide tube implantation for electrophysiologic examination and harvesting of histologic samples.

The MAPs of the diaphragm were recorded along with the visual observation of diaphragm movement. An en bloc $10-\mathrm{cm}-$ long segment of the phrenic nerve, including the pericardium and diaphragm, was taken for histologic examination.

Animal care, housing, and surgery were performed in accordance with the "Guidelines for Animal Experimentation of the Animal Experimentation Committee," Kyoto University (1983).
TABLE 1. Experimental results of phrenic nerve regeneration with a polyglycolic acid and collagen tube

\begin{tabular}{|c|c|c|c|c|c|c|c|c|c|}
\hline \multirow[b]{2}{*}{ Dog } & \multicolumn{5}{|c|}{ Group I } & \multicolumn{4}{|c|}{ Group II } \\
\hline & 1 & 2 & 3 & 4 & 5 & 6 & 7 & 8 & 9 \\
\hline XP examination & $\mathrm{N}$ & $\mathrm{N}$ & $Y$ & $\mathrm{~N}$ & $\mathrm{~N}$ & $Y$ & $Y$ & $Y$ & $\mathrm{~N}$ \\
\hline MAP & $\mathrm{N}$ & $\mathrm{N} / \mathrm{A}$ & $Y$ & N/A & $\mathrm{N} / \mathrm{A}$ & $\mathrm{N} / \mathrm{A}$ & $Y$ & $Y$ & $\mathrm{~N} / \mathrm{A}$ \\
\hline Result & $\mathrm{N}$ & $\mathrm{N}$ & $Y$ & $\mathrm{~N}$ & $\mathrm{~N}$ & Y & $Y$ & $Y$ & $\mathrm{~N}$ \\
\hline Remark & \multicolumn{5}{|c|}{ Preliminary } & \multicolumn{3}{|l|}{ * } & $\dagger$ \\
\hline
\end{tabular}

$X P$, radiologic; $M A P$, muscle action potential; $X P$ examination: $Y$, Diaphragm moved; $N$, diaphragm not moved; MAP: $Y$, MAP recorded; $N$, MAP not recorded; $N / A$, not applicable. Repair was successful in 1 of 5 dogs in group I without fat pad coverage and in 3 of 4 dogs in group II with pedicled pericardial fat pad coverage. Group I: without fat tissue coverage. Group II: with fat tissue coverage. *Histologic examinations are shown on this report. $\dagger$ MAPs are shown on this report.

\section{Results}

The results obtained in the 9 dogs are summarized in Table 1. All of the dogs survived more than 12 months without symptoms or respiratory disorders.

\section{Radiographic Examinations}

No movement of the diaphragm was observed in any of the dogs up to 3 months. (One dog underwent open thorax examination 1 month after implantation for preliminary study.) Four months after the implantation, 1 of the 5 dogs in group I showed synchronized movement of both sides of the diaphragm, and 3 of $4 \mathrm{dogs}$ in group II showed such synchronized movement. In the remaining animals of both groups, the diaphragm on the implantation side remained elevated and immobile until the end of observation (Figure 4).

\section{Histologic Examinations}

The movement of the diaphragm was checked directly by open thoracotomy in the $4 \mathrm{dogs}$ showing synchronized

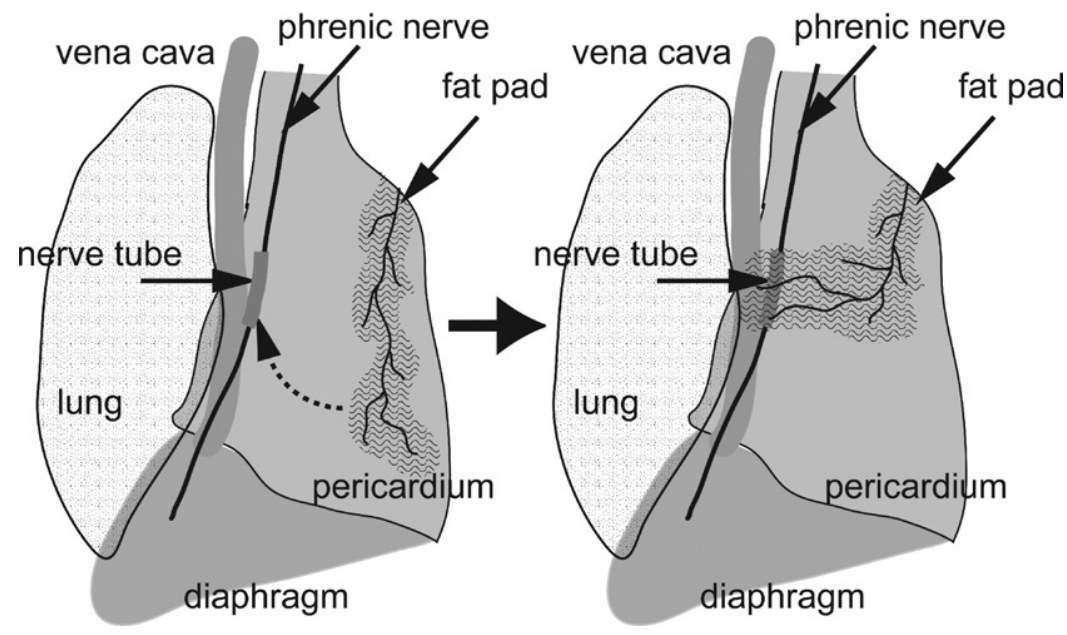

Figure 3. Surgical procedure for covering with a pedicled pericardial fat pad: A pedicled pericardial fat pad with a blood supply originating from the internal thoracic artery is detached from the pericardium and rotated to cover the site of tube implantation. 


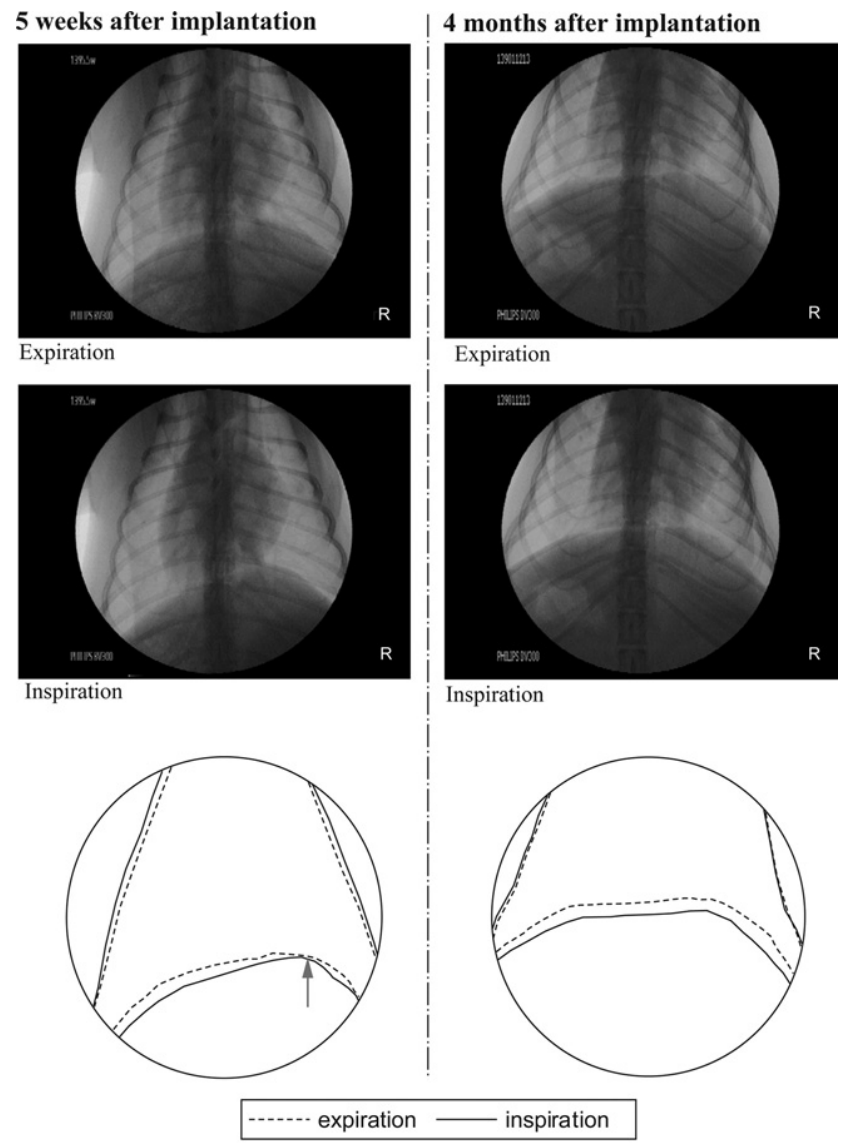

*These outlines(below) were traced at the maximum expiration and inspiration.

Figure 4. Still image of the maximum expiration and inspiration, obtained and traced from an x-ray film record 5 weeks (left) and 4 months (right) after implantation in the same dog: At 5 weeks after the operation, the paralyzed diaphragm (right side of the $\mathrm{dog}$ ) is elevated and immobile, and at 4 months, both sides of the diaphragm are moving synchronously.

diaphragm movement by x-ray film examination (Figure $\mathrm{E} 1, A, B)$. The light microscopic findings for 1 of these dogs are shown in Figure E2. The proximal part of the phrenic nerve showed a normal structure of the nerve fibers and myelin sheaths (Figure E2, A). At the site of reconstruction, where a $1-\mathrm{cm}-$ long segment of the nerve had been totally resected and the guide tube implanted, regenerated nerve fibers were recognized, the diameters of the axons were smaller, and the myelin sheaths were thinner than in the proximal part of the nerve (Figure E2, B). At $1 \mathrm{~cm}$ distal to the implanted guide tube, the nerves and accompanying myelin sheaths were also found to have regenerated (Figure $\mathrm{E} 2, C)$. On average, the nerve fibers were smaller and the myelin sheaths were thinner than in the proximal part of the nerve.

In the dogs of both groups that showed no diaphragm movement, no bridging tissue had formed between the nerve stumps at the site of reconstruction.

Transmission electron microscopy demonstrated regeneration of both myelinated and unmyelinated nerve fibers (Figure E3). Figure E3, $A$ shows that at $1 \mathrm{~cm}$ proximal to the implanted tube, the nerve had a normal structure, consisting of myelinated nerve fibers accompanied by Schwann cells and unmyelinated nerve fibers with a smaller diameter. Figure E3, $B$ shows that where the tube had been implanted, the nerve fibers had evidently regenerated, although the myelin sheaths were thinner than those shown in Figure E3, $A$. Figure E3, $C$ shows the area $1 \mathrm{~cm}$ distal to the implanted tube. Here, the nerve fibers had clearly regenerated, although the diameter of the axons was smaller and the myelin sheaths were thinner than those on the proximal side.

The results of morphometric analysis are shown in Table 2. At 12 months after reconstruction, the axonal density was higher than that of the normal control nerve in the proximal phrenic component, midportion, and distal phrenic nerve. In contrast, the axonal diameter, total area of neural tissue, and thickness of the myelin sheath were less than those of normal nerves.

MAPs were recorded from electrodes on the diaphragm after stimulation of the phrenic nerve $3 \mathrm{~cm}$ proximal to the implanted tube (Figure 5, A). The first component of the recorded wave was an $M$ wave, indicating reinnervation of the muscle with fibers. MAPs were recorded from the diaphragm on the contralateral intact (control) side (Figure 5, B). Although the conduction velocity was slower and the amplitude was smaller on the reconstructed side than on the control side, the wave patterns were similar on both sides, perhaps indicating that the regenerated phrenic nerve had characteristics similar to those of the normal nerve. To confirm that reinnervation had occurred through the recon-

TABLE 2. Morphometric analysis of nerve cross-sections 12 months after implantation and normal control phrenic nerves

\begin{tabular}{|c|c|c|c|c|}
\hline & $\begin{array}{l}\text { Proximal phrenic } \\
\text { component }\end{array}$ & $\begin{array}{l}\text { Midportion of the } \\
\text { regenerated segment }\end{array}$ & $\begin{array}{c}\text { Distal phrenic } \\
\text { nerve }\end{array}$ & Normal control \\
\hline Diameter of myelinated nerve fiber (mean $\pm S D, \mu \mathrm{m}$ ) & $10.8 \pm 1.9$ & $7.1 \pm 2.4$ & $7.3 \pm 2.5$ & $8.6 \pm 3.5$ \\
\hline Density of myelinated nerve fiber (counts/100 $\times 100 \mu \mathrm{m}^{2}$ ) & 81 & 152 & 92 & 124 \\
\hline Percentage of neural tissue $(\%)$ & 46 & 55 & 31 & 44 \\
\hline Thickness of myelin sheath (mean $\pm \mathrm{SD}, \mu \mathrm{m})$ & $1.9 \pm 1.8$ & $0.8 \pm 0.2$ & $1.0 \pm 0.4$ & $1.8 \pm 0.6$ \\
\hline
\end{tabular}

$S D$, Standard deviation. 
A

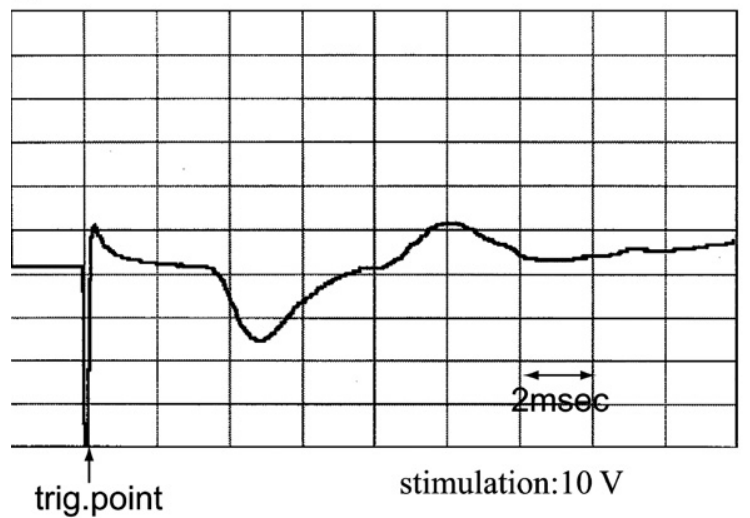

B

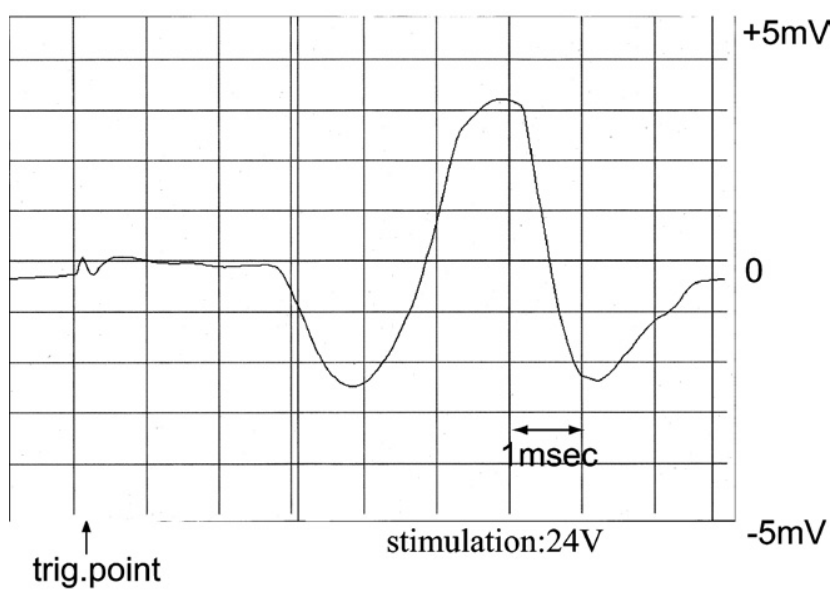

Figure 5. A, MAPs examined on a group II dog 12 months after tube implantation (top), recorded from electrodes placed on the diaphragm by stimulating the proximal side of the phrenic nerve: The $\mathbf{M}$ wave is observed at $3.5 \mathrm{msec}$ after the trigger point, and the amplitude is lower than the control (bottom), although the wave pattern is similar. B, MAPs examined in the same way at the left phrenic nerve (not implanted) of a group II dog: The M wave is observed $2.8 \mathrm{msec}$ after the trigger point, and the MAP of the diaphragm shows a normal wave pattern. MAP, Muscle action potential.

structed segment (ie, to rule out a bypass route), the MAP was examined again after resection of this regenerated part of the nerve for histologic examination. The MAP became flat after resection, indicating that stimulation had occurred through the regenerated nerve and not through another route.

\section{Discussion}

Human peripheral nerves are capable of regenerating at a rate of $1 \mathrm{~mm}$ per day, and injured peripheral nerves sometimes regenerate spontaneously. ${ }^{5}$ However, in most cases, when left untreated, the ends of a severed nerve do not connect with each other, and the proximal end forms a neuroma while the distal part degenerates, which may cause paralysis and/or numbness. ${ }^{19,20}$

There have been several previous clinical trials of phrenic nerve reconstruction. Schoeller and colleagues ${ }^{6}$ reported a $76-$ year-old man with a malignant thymoma for whom immediate reconstruction to close a $3-\mathrm{cm}$ resected gap was carried out with an autograft from the sural nerve. The function of the diaphragm was restored 9 months after this procedure. Brouillette and colleagues ${ }^{5}$ reported a 16-month-old infant with a teratoma in whom unilateral diaphragm function was restored 10 months after end-to-end anastomosis of the nerve ends by the resection of the tumor. Merav and colleagues ${ }^{4}$ reported a 20 -year-old trauma patient in whom a sural nerve autograft was used to replace a 3-cm gap in the phrenic nerve. They observed a significant improvement of diaphragm motion 13 months after reconstruction.

As for the method used to reconstruct injured peripheral nerves, direct anastomosis is considered to be the first choice in patients in whom the defect is shorter than $5 \mathrm{~mm}$. For longer nerve gaps, autografting and nerve tube implantation have been adopted. Autografting has been considered the "gold standard" in peripheral nerve surgery, although in terms of motor recovery the results are not always satisfactory. For example, Moneim and $\mathrm{Omer}^{21} \mathrm{de}-$ scribed in their textbook that only $28 \%$ of patients recover their motor function after autografting. Furthermore, autografting essentially results in donor site morbidity.

A recent study using a canine peroneal nerve model indicated that reconstruction using a nerve tube gives better results than autografting in terms of not only pathologic findings but also functional parameters. ${ }^{14}$

Various types of materials have been used to make nerve tubes, such as silicon, ${ }^{22}$ PGA, ${ }^{23}$ and collagen. ${ }^{24,25}$ Among them, a nerve guide tube made of PGA is already commercially available, but it can only be used to repair gaps up to $30 \mathrm{~mm}$ in minor sensory nerves and is not indicated for reconstruction of motor nerves. We developed a new bioresorbable PGA-collagen tube that is filled with collagen sponge to enhance nerve regeneration. ${ }^{13}$ As a scaffold for in situ tissue engineering, collagen provides ideal properties for the growth of living tissue. ${ }^{14,16,26}$ Collagen has also been applied in thoracic surgery for use in an artificial esophagus ${ }^{27}$ and in artificial tracheas. ${ }^{27}$

On the basis of the promising results obtained in animal experiments, nerve guide tubes have already been applied clinically to more than 150 patients with nerve injury. ${ }^{15,16}$ However, in most cases, the nerve tubes were implanted at sites surrounded by vascular-rich subcutaneous tissue. ${ }^{20}$ The phrenic nerve, on the other hand, is located in a vascular-poor environment within the thoracic cavity: It runs along the pericardium without a plentiful blood supply. Furthermore, it is exposed to pleural effusion and continuously abraded by the lung. 
To create a better environment for the phrenic nerve regeneration, we applied a pedicled pericardial fat pad in group II of the present study. Such a pedicle is currently used clinically in cardiothoracic surgery.

For example, pedicled pericardial fat pad grafts have been used to reinforce bronchial closure after pulmonary resection because they have a fairly constant blood supply from the pericardial artery, branched from the internal thoracic artery. ${ }^{28}$ Thus, pericardial fat tissue seemed to have the potential to induce neovascularization and produce cytokines related to tissue repair. For repair of tissue that has been damaged surgically, it is advantageous to provide a blood supply and cytokines. ${ }^{29}$ This method of using pedicled pericardial fat pad might provide a function similar to that of the vascularized nerve graft described by Lundborg. ${ }^{20}$

In the present study, the phrenic nerve was regenerated through the guide tube and diaphragm movement was recovered in 3 of 4 dogs in group II. Although the number of dogs was not sufficient, this difference might indicate the benefit of a fat pad graft. Pathologically, neither sprouting nor neuroma occurred at the reconstruction site. In contrast, in the dogs whose diaphragm function did not recover, no bridging tissue was observed between the 2 nerve ends at the site of tube implantation, perhaps because of tube failure before the nerve regeneration.

Ultrastructural observations showed that the diameter of axons at the regenerated site was smaller and that the myelin sheaths were thinner than those on the proximal control side. These findings were consistent with the data obtained by electrophysiologic study of conduction velocity, that is, the $\mathrm{M}$ wave in the regenerated nerve was slower than in the control. In this context, the conduction velocity of a motor nerve is well known to be related to axonal diameter.

In situ tissue engineering is a new approach in which an adequate environment is proved in the body to encourage regeneration of a tissue defect. The PGA-collagen nerve guide tube we used has sufficient space for elongation of the nerve tissue, and the collagen sponge filling provides an adequate environment for nerve regeneration. With the assistance of a pedicled pericardial fat pad, the injured phrenic nerve regenerated and restored its motor nerve function.

Because the clinical trial has already begun on this PGAcollagen nerve guide tube, in which some promising results have been reported for the injuries of other peripheral nerves, ${ }^{12,13}$ the use of the PGA-collagen tube for the phrenic nerve may also become a good alternative to conventional auto nerve grafting, which is accompanied with the risk of donor site morbidity.

\section{Conclusions}

Regeneration of the phrenic nerve across a 1-cm gap was achieved successfully using a bioabsorbable artificial nerve guide tube made of PGA and collagen sponge. Coverage by a pedicled pericardial fat pad at the site of tube implantation seemed effective for aiding repair of the nerve. This reconstruction technique will be useful for treatment of selected cases of phrenic nerve injury accompanied by nerve defect.

The authors thank Drs Toshinari Toba and Yasuhiko Shimizu at the Institute for Frontier Medical Sciences, Kyoto University, for supervision.

\section{References}

1. Tripp HF, Bolton JW. Phrenic nerve injury following cardiac surgery: a review. J Card Surg. 1998;13:218-23.

2. Simansky DA, Paley M, Refaely Y, Yellin A. Diaphragm plication following phrenic nerve injury: a comparison of paediatric and adult patients. Thorax. 2002;57:613-6.

3. Ishii $\mathrm{K}$, Kurosawa $\mathrm{H}$, Koyanagi $\mathrm{H}$, et al. Effects of bilateral transvenous diaphragm pacing on hemodynamic function in patients after cardiac operations. Experimental and clinical study. J Thorac Cardiovasc Surg. 1990;100:108-14.

4. Merav AD, Attai LA, Condit DD. Successful repair of a transected phrenic nerve with restoration of diaphragmatic function. Chest. 1983; 84:642-4.

5. Brouillette RT, Hahn YS, Noah ZL, Ilbawi MN, Wessel HU. Successful reinnervation of the diaphragm after phrenic nerve transection. J Pediatr Surg. 1986;21:63-5.

6. Schoeller T, Ohlbauer M, Wechselberger G, Piza-Katzer H, Margreiter R. Successful immediate phrenic nerve reconstruction during mediastinal tumor resection. J Thorac Cardiovasc Surg. 2001;122:1235-7.

7. Mackinnon SE, Dellon AL. A study of nerve regeneration across synthetic (Maxon) and biologic (collagen) nerve conduits for nerve gaps up to $5 \mathrm{~cm}$ in the primate. J Reconstr Microsurg. 1990;6:117-21.

8. Mikos AG, Sarakinos G, Leite SM, Vacanti JP, Langer R. Laminated three-dimensional biodegradable foams for use in tissue engineering. Biomaterials. 1993;14:323-30.

9. Heath CA, Rutkowski GE. The development of bioartificial nerve grafts for peripheral-nerve regeneration. Trends Biotechnol. 1998;16: 163-8.

10. Kiyotani T, Teramachi M, Takimoto Y, Nakamura T, Shimizu Y, Endo K. Nerve regeneration across a $25-\mathrm{mm}$ gap bridged by a polyglycolic acid-collagen tube: a histological and electrophysiological evaluation of regenerated nerves. Brain Res. 1996;740:66-74.

11. Kitahara AK, Suzuki Y, Qi P, et al. Facial nerve repair using a collagen conduit in cats. Scand J Plast Reconstr Surg Hand Surg. 1999;33:187-93.

12. Matsumoto K, Ohnishi K, Kiyotani T, et al. Peripheral nerve regeneration across an 80-mm gap bridged by a polyglycolic acid (PGA)collagen tube filled with laminin-coated collagen fibers: a histological and electrophysiological evaluation of regenerated nerves. Brain Res. 2000;868:315-28.

13. Toba T, Nakamura T, Lynn AK, et al. Evaluation of peripheral nerve regeneration across an 80-mm gap using a polyglycolic acid (PGA) collagen nerve conduit filled with laminin-soaked collagen sponge in dogs. Int J Artif Organs. 2002;25:230-7.

14. Nakamura T, Inada Y, Fukuda S, et al. Experimental study on the regeneration of peripheral nerve gaps through a polyglycolic acidcollagen (PGA-collagen) tube. Brain Res. 2004;1027:18-29.

15. Hagiwara A, Nakashima S, Itoh T, et al. [Clinical application of PGA-tube for regeneration of intrapelvic nerves during extended surgery for intrapelvic recurrent rectal cancer]. Gan To Kagaku Ryoho. 2002;29:2202-4.

16. Inada Y, Morimoto S, Takakura Y, Nakamura T. Regeneration of peripheral nerve gaps with a polyglycolic acid-collagen tube. Neurosurgery. 2004;55:640-6; discussion 646-8.

17. Kanemaru S, Nakamura T, Omori K, et al. Recurrent laryngeal nerve regeneration by tissue engineering. Ann Otol Rhinol Laryngol. 2003; 112:492-8. 
18. Ito T, Nakamura T, Takagi $\mathrm{T}$, et al. Biodegradation of polyglycolic acid-collagen composite tubes for nerve guide in the peritoneal cavity. Asaio J. 2003;49:417-21.

19. Ide C. Peripheral nerve regeneration. Neurosci Res. 1996;25:101-21.

20. Lundborg G. A 25-year perspective of peripheral nerve surgery: evolving neuroscientific concepts and clinical significance. J Hand Surg [Am]. 2000;25:391-414.

21. Moneim MSA, Omer OG. Clinical outcome following acute nerve repair. In: Omer GE, Spinner M, Van Beek A, eds. Management of peripheral nerve problems. Philadelphia, PA: 1998:414-9.

22. Tong XJ, Hirai $\mathrm{K}$, Shimada $\mathrm{H}$, et al. Sciatic nerve regeneration navigated by laminin-fibronectin double coated biodegradable collagen grafts in rats. Brain Res. 1994;663:155-62.

23. Mackinnon SE, Dellon AL. Clinical nerve reconstruction with a bioabsorbable polyglycolic acid tube. Plast Reconstr Surg. 1990;85:419-24.

24. Hentz VR, Rosen JM, Xiao SJ, McGill KC, Abraham G. The nerve gap dilemma: a comparison of nerves repaired end to end under tension with nerve grafts in a primate model. J Hand Surg [Am]. 1993;18:417-25.
25. Lundborg G, Dahlin L, Dohi D, Kanje M, Terada N. A new type of "bioartificial" nerve graft for bridging extended defects in nerves. J Hand Surg [Br]. 1997;22:299-303.

26. Hori Y, Nakamura T, Matsumoto K, Kurokawa Y, Satomi S, Shimizu Y. Experimental study on in situ tissue engineering of the stomach by an acellular collagen sponge scaffold graft. Asaio J. 2001;47:206-10.

27. Yamamoto Y, Nakamura T, Shimizu Y, et al. Intrathoracic esophageal replacement in the dog with the use of an artificial esophagus composed of a collagen sponge with a double-layered silicone tube. J Thorac Cardiovasc Surg. 1999;118:276-86.

28. Anderson TM, Miller JI Jr. Surgical technique and application of pericardial fat pad and pericardiophrenic grafts. Ann Thorac Surg. 1995;59:1590-1.

29. Ichinose Y, Asoh H, Yano T, et al. Use of a pericardial fat pad flap for preventing bronchopleural fistula: an experimental study focusing on the angiogenesis and cytokine production of the fat pad. Surg Today. $1995 ; 25: 811-5$.

To assure fairness to authors submitting work for consideration in The Journal of Thoracic and Cardiovascular Surgery, a mechanism exists for managing conflicts of interest. The editor and each of the section editors complete a "Conflict of Interest" form that identifies any and all relationships with commercial and other academic entities. When the editor has a potential conflict because of a relationship with another entity or author, the editor appoints an alternate editor from among the section editors or editorial board members who assumes the entire responsibility for final decisions on the manuscript in question. The editor does not read the reviews that are submitted nor engage in discussing the manuscript prior to the final decision. When the conflict of interest involves a section editor, a "guest section editor" is appointed who fills the role normally played by the conflicted section editor. All members of the editorial board and reviewers are asked to indicate any conflict of interest when they agree to review a manuscript. 

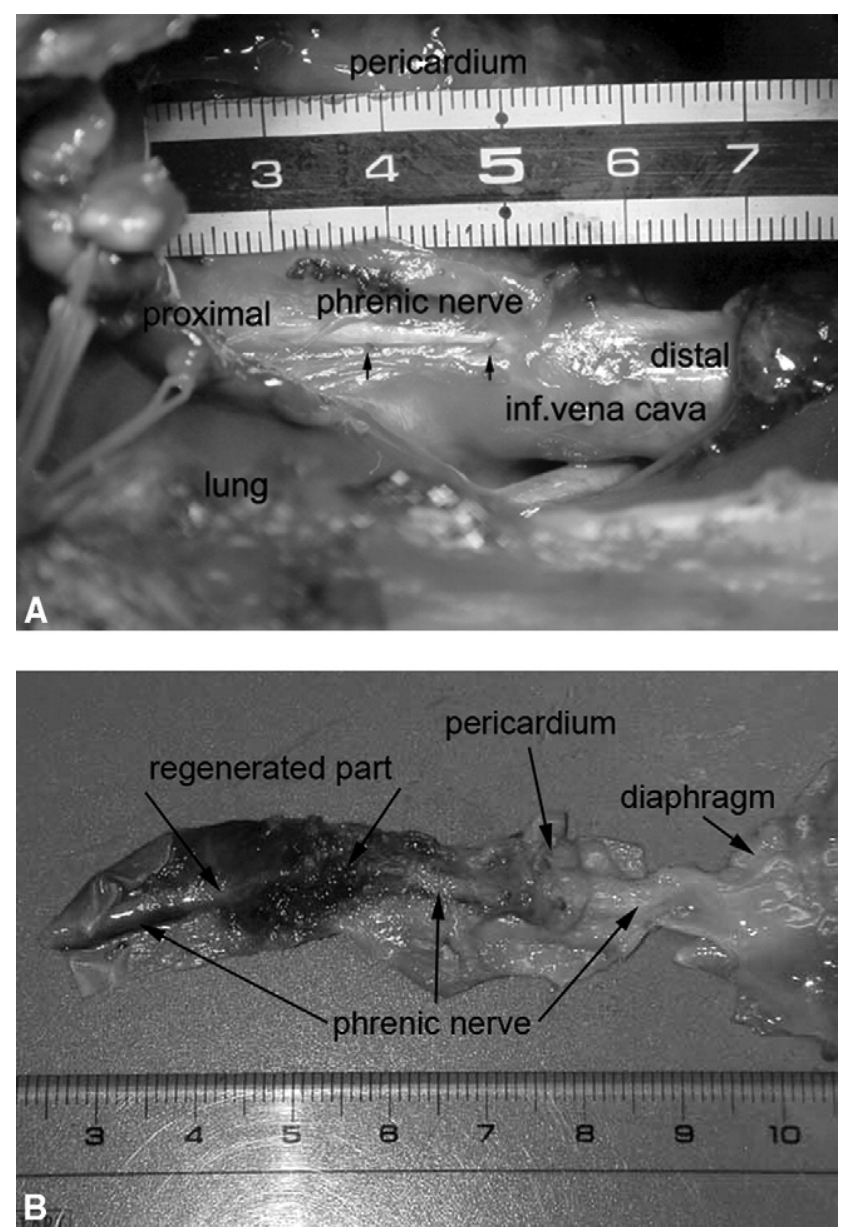

Figure E1. A, Open thorax view of the site of reconstruction 4 months after tube implantation: The regenerated nerve can be seen between the suture knots. B, Gross view of the phrenic nerve harvested en bloc with the pericardium and diaphragm showing the proximal side of the implanted/regenerated part to the diaphragm 12 months after implantation in a group II dog: Adhesive tissue is present around the area of the implanted tube, and the phrenic nerve runs continuously to the diaphragm. 

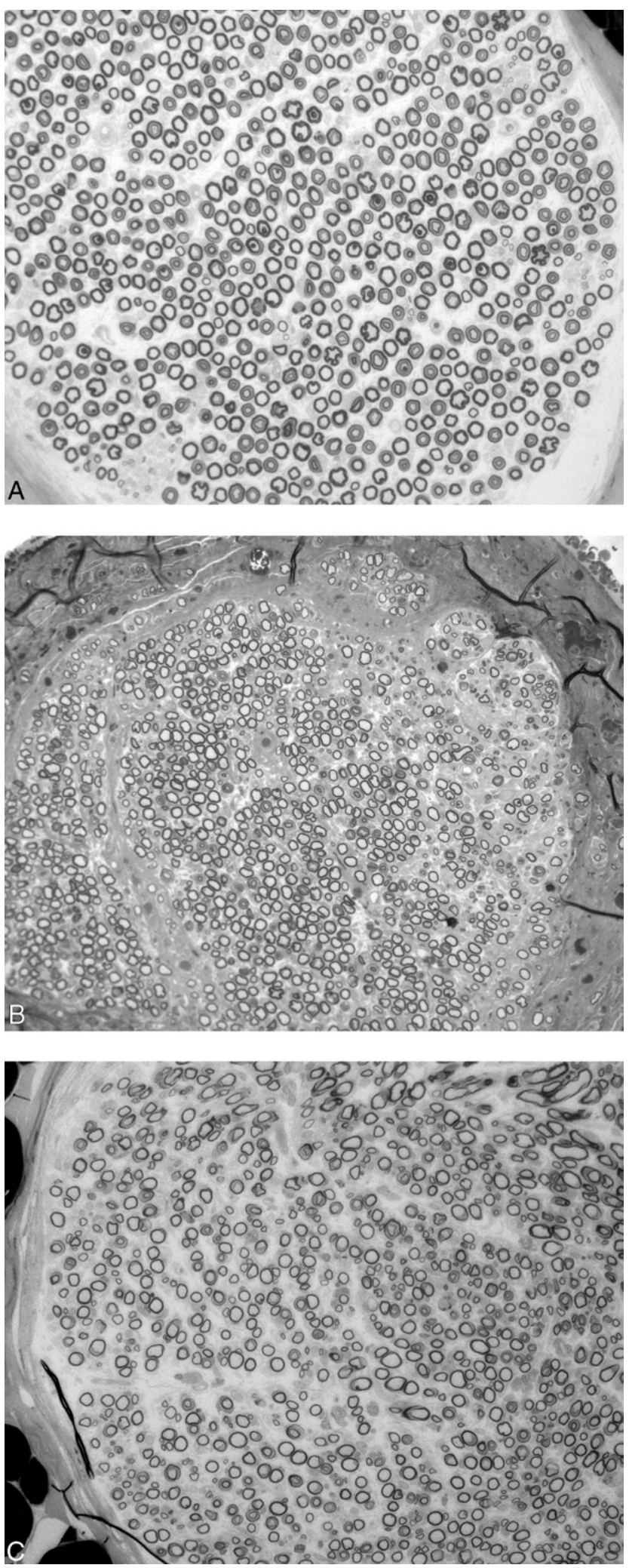

Figure E2. A, Light microscopic transverse section $2 \mathrm{~cm}$ proximal to the side of tube implantation in a group II dog, harvested 12 months after implantation. Toluidine blue stain $\times 400$ : The normal phrenic nerve composition is evident (Figures $A$ to $C$ were obtained from the same dog). B, Light microscopic transverse section through the center of the tube implantation site in a group II dog, harvested 12 months after implantation, Toluidine blue stain $\times 400$ : Although the number and the diameters of the fibers are smaller, the nerve fibers have clearly regenerated. C, Light microscopic transverse section $2 \mathrm{~cm}$ distal to the site of tube implantation in a group II dog, harvested 12 months after implantation. Toluidine blue stain $\times 400$ : Various sizes of fibers are present, suggesting that some have regenerated. 

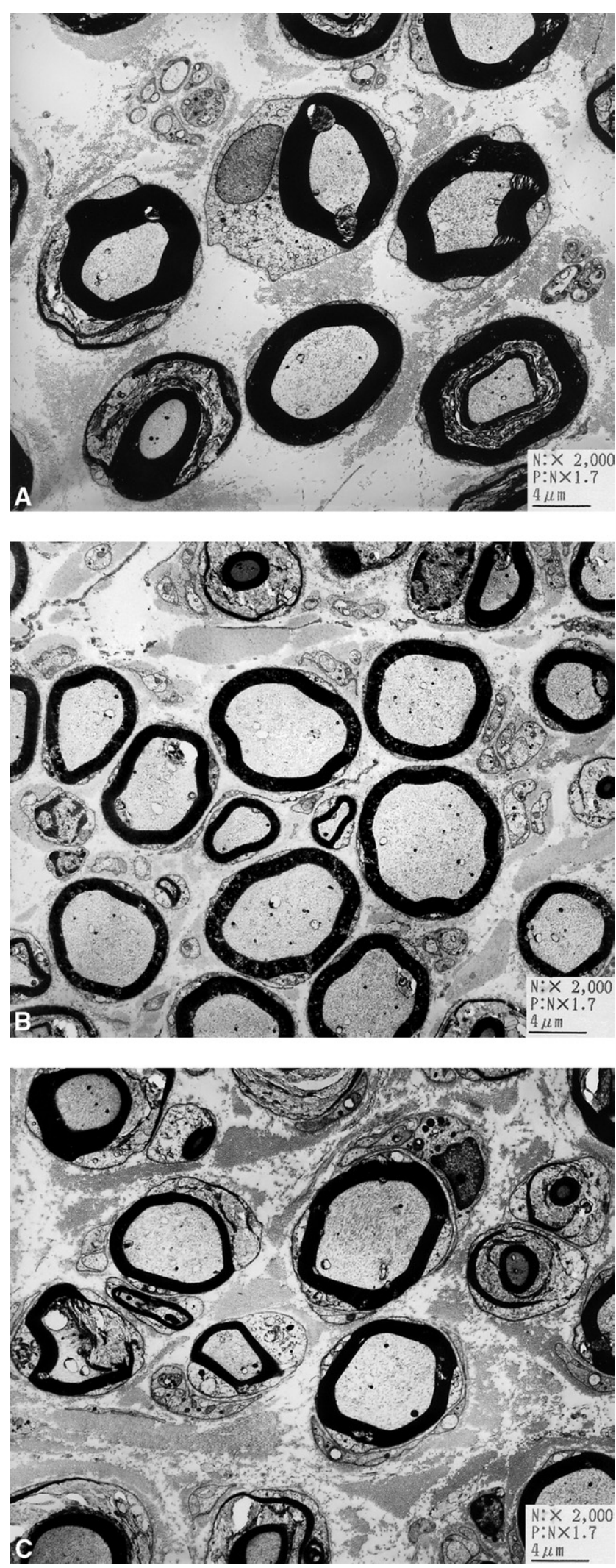

Figure E3. A, Transmission electron micrograph of the proximal phrenic nerve of a group II dog, harvested 12 months after tube implantation, $2 \mathrm{~cm}$ proximal to the distal side of cut end: Myelinated and unmyelinated fibers and Schwann cells are observed. (Figure E3, A, B, C is obtained from the same dog.) B, Transmission electron micrograph of a nerve tube implanted in the phrenic nerve of a group II dog, harvested 12 months after the implantation, in the center of the area where the tube was implanted: All the fibers are regenerated nerve fibers, including the myelinated and unmyelinated fibers; the wall of the nerve fibers is thinner than on the proximal side (Figure E3, A). C, Transmission electron micrograph of the distal phrenic nerve of a group II dog, harvested 12 months after tube implantation, $2 \mathrm{~cm}$ distal to the distal cut end: Some thin-walled and some thick-walled fibers are observed, together with myelinated and unmyelinated fibers, and the wall of the nerve fibers is thinner than on the proximal side (Figure E3, A). 